\title{
Evaluating Linear Second Order Homogenous Differential Equations Using the Finite Difference Schemes
}

\author{
Ben Johnson Obakpo ${ }^{1}$, Odama Moses Owan ${ }^{2}$, Charity Ebelechukwu Okorie ${ }^{3}$. \\ ${ }^{I}$ Department of Mathematics and Statistics, Federal University Wukari, Taraba State, Nigeria. \\ ${ }^{2}$ Department of Mathematics and Statistics, Federal University Wukari, Taraba State, Nigeria. \\ ${ }^{3}$ Department of Mathematics and Statistics, Federal University Wukari, Taraba State, Nigeria.
}

\begin{abstract}
Difference equations are difficult problems, and rarely can an analytic formula be found for the solution. The problems of difference equations are those of existence, uniqueness and stability of solutions subject to various types of initial two - point or multipoint boundary conditions. Other problems include the behavior of solution with constant and variable coefficients, the stability and instability of linear and non-linear difference equations. This study was designed to evaluate ordinary differential equations and to test the stability of solutions to difference equation using difference methods. In this work the finite difference method was used which is made up of the forward, backward and the central difference approximations. These techniques were used to evaluate two sample problems of general linear second order differential equations. After solving each problem their error estimates were evaluated. This was done in order to check the level of accuracy and the stability of their solutions and to determine which method or technique is more efficient. It was found that the central difference method was more accurate than other methods having that its error is of order $h^{2}\left(i . e . \mathrm{oh}^{2}\right)$ as compared to oh in the other cases.
\end{abstract}

Key Words: Differential equations, difference methods, Stability, ordinary, homogenous.

\section{Introduction}

A difference equation is an equation for some unknown function, involving one or more derivatives of the unknown function. Peter Philip (July 22, 2016)[12]. Differential equations are solved by integration, but unfortunately, for many practical applications in science and engineering, systems of differential equations cannot be integrated to give an analytical solution, but rather need to be solved Numerically, Karline Soetaert, Thomas Petzoldt and R Woodrow Setzer (2010)[5].

The concept of difference equation is on e that has to do with the differences between successive values of a function of an integer variable. It can be regarded as the discrete version of a differential equation. For example the difference equation

$f(n+1)-f(n)=g(n)$ is the discrete version of the differential equation $f^{\prime}(x)=g(x)$. We can see difference equation from at least three points of views: as sequence of number, discrete dynamical system and iterated function. Difference Equations By Forward Difference Operator Method" by Odior and Charles-Owaba(2003)[9] and the second "Finite Differences versus Finite elements for Solving Nonlinear integro-differential Equations" written by Beny Neta and Jerome, (1985) have been published.[3]. Each of these studies focused on one or two of the finite difference schemes. Difference equation can also exist in the form of a linear difference equation with $\mathrm{y}_{\mathrm{n}+1}, \mathrm{y}_{\mathrm{n}+2}$, -- etc. A linear difference equation with constant coefficient

$\mathrm{y}_{\mathrm{n}+\mathrm{r}}+\mathrm{a}_{\mathrm{r}} \mathrm{y}_{\mathrm{n}+\mathrm{r}-1}+\mathrm{a}_{\mathrm{r}} \mathrm{y}_{\mathrm{n}+\mathrm{r}-2}+\ldots+\mathrm{a}_{\mathrm{r}} \mathrm{y}_{\mathrm{n}}=-\mathrm{f}(\mathrm{n})$

when $-\mathrm{f}(\mathrm{n})=0$ then equation (1.1) is said to be a linear homogenous difference equation with constant coefficient (Grewal, 1998)[4]. The non or inhomogeneous difference equation $a_{n+1}=a_{n}+1$----- 1.2 (Stein, 1990)[13] also exist as relations between certain orthogonal functions like in the case of Bessel functions given by $\mathrm{J}_{\mathrm{v}-1+} \mathrm{J}_{\mathrm{v}+1}=2 \mathrm{v} / \mathrm{x} \mathrm{J}_{\mathrm{v}}$-------- 1.3 (Olayi, 2001) [10].

\section{METHODOLOGY}

Out of the difference methods used in finding solutions to difference equations, in this work, our emphasis will be laid on two difference methods and the stability of their solutions. These methods are the central difference method and finite difference method. The finite difference method contains a summary of both so we may likely be using the finite method in most cases.

\section{THE CENTRAL DIFFERENCE METHOD}

The central difference method contains the even and the odd differences and this is why it is preferred to the other difference methods.

The central difference formula can be obtained using the Taylor series expansion. For an illustration we can derive the formula for a second - order Taylor series $\mathrm{F}^{\mathrm{ll}}(\mathrm{x})$ of order $\mathrm{O}\left(\mathrm{h}^{2}\right)$, where $\mathrm{O}\left(\mathrm{h}^{2}\right)$ is the error term and is the step size. 
Let $\mathrm{f}_{\mathrm{k}}=\mathrm{f}\left(\mathrm{x}_{0}+\mathrm{kh}\right)$, for $\mathrm{k}=-3,-2,-1,0,1,2,3$.

First we start with the Taylor series expansion

$\mathrm{F}(\mathrm{x}+\mathrm{h})=\mathrm{f}(\mathrm{x})+\mathrm{hf}^{1}(\mathrm{x})+\frac{h^{2} f^{11}(x)}{2 !}+\frac{h^{3} f^{111}(x)}{3 !}+\ldots \ldots \ldots \ldots \ldots \ldots \ldots . . .2 .1$

$\mathrm{F}(\mathrm{x}-\mathrm{h})=\mathrm{f}(\mathrm{x})-\mathrm{hf}^{1}(\mathrm{x})+\frac{h^{2} f^{11}(x)}{2 !}-\frac{h^{3} f^{111}(x)}{3 !}+\ldots \ldots \ldots \ldots \ldots \ldots \ldots \ldots \ldots . .2 .2$

Adding equation (2.1) and (2.2) will eliminate the terms involving the odd derivative

$f^{1}(x), f^{3}(x), f^{5}(x),-----$

$\mathrm{f}(\mathrm{x}+\mathrm{h})+\mathrm{f}(\mathrm{x}-\mathrm{h})=2 \mathrm{f}(\mathrm{x})+\frac{2 h^{2} f^{11}(x)}{2 !}+\frac{2 h^{4} f^{4}(x)}{4 !}$

Solving equation (2.3) for $\mathrm{f}^{11}(\mathrm{x})$ yields

$\mathrm{f}^{11}(\mathrm{x})=\frac{f(x+h)-2 f(x)+f(x-h)}{h^{2}}-\frac{2 h^{2} f^{4}(x)}{4 !} \ldots \ldots \ldots-\frac{2 h^{2(x)} f^{(2 x)}(x)}{(2 x) !} \ldots \ldots .2 .4$

If the series in (2.4) is truncated at the fourth derivative, there exists a value that lies in $[\mathrm{x}-\mathrm{h}, \mathrm{x}+\mathrm{h}]$ so that $\mathrm{f}^{11}\left(\mathrm{x}_{0}\right)=\frac{f_{1}-2 f_{0}+f_{1}}{h^{2}}$ -

$\frac{h^{2} f^{(4)}}{12}$

$\mathrm{f}^{11}\left(\mathrm{x}_{0}\right)=\frac{f_{1}-2 f_{0}+f_{1}}{h^{2}}+\mathrm{O}\left(\mathrm{h}^{2}\right)$

This gives us the desired formula for approximating $\mathrm{f}^{11}(\mathrm{x})$

$\mathrm{f}^{11}(\mathrm{x}) \approx \frac{f_{1}-2 f_{0}+f_{1}}{h^{2}}$

The accuracy of this formula depends on the step size (Matthews, 2004)[8]

\section{THE FINITE DIFFERENCE METHOD}

The finite difference approximations to the various derivatives are derived as follows;

If $\mathrm{f}(\mathrm{x})$ and its derivative are simple-values continuous functions of $\mathrm{x}$ then by Taylor's expansion, we have

$\mathrm{y}(\mathrm{x}+\mathrm{h})=\mathrm{y}(\mathrm{x})+\mathrm{hy}^{1}(\mathrm{x})+\frac{h^{2} y^{11}(x)}{2 !}+\frac{h^{3} y^{111}(x)}{3 !}+\frac{h^{4} y^{i v}(x)}{4 !}+$

and $\mathrm{y}(\mathrm{x}-\mathrm{h})=\mathrm{y}(\mathrm{x})-\mathrm{hy}^{1}(\mathrm{x})+\frac{h^{2} y^{11}(x)}{2 !}-\frac{h^{3} y^{111}(x)}{3 !}+\frac{h^{4} y^{i v}(x)}{4 !}$

solving $\mathrm{y}^{1}(\mathrm{x})$ in equation 3.8 yields $\quad \mathrm{y}^{1}(\mathrm{x})=\frac{1}{h}[\mathrm{y}(\mathrm{x}+\mathrm{h})-\mathrm{y}(\mathrm{x})]-\frac{h y^{11}(x)}{2}$

that is, $\quad \mathrm{y}^{1}(\mathrm{x})=\frac{1}{h}[\mathrm{y}(\mathrm{x}+\mathrm{h})-\mathrm{y}(\mathrm{x})]+\mathrm{O}(\mathrm{h})$

which is the forward difference approximation of $y^{1}(x)$ with an error of order $h$.

similarly 2.9 gives:

$$
\mathrm{y}^{1}(\mathrm{x})=\frac{1}{h}[\mathrm{y}(\mathrm{x})-\mathrm{y}(\mathrm{x}-\mathrm{h})]+\mathrm{O}(\mathrm{h})
$$

which is the backward difference approximation of $y^{1}(x)$ with an error of order $h$.

Subtracting 2.9 from 2.8 we obtain

$\mathrm{y}^{1}(\mathrm{x})=\frac{1}{2 h}\left[\mathrm{y}(\mathrm{x}+\mathrm{h})-\mathrm{y}(\mathrm{x}-\mathrm{h})+\mathrm{O}\left(\mathrm{h}^{2}\right)\right]$

which is the central difference approximation $\mathrm{y}^{1}(\mathrm{x})$ with an error of the order $\mathrm{h}^{2}$. The central difference approximation to $\mathrm{y}^{1}(\mathrm{x})$ is better than the forward $(\Delta)$ or backward $(\nabla)$ difference approximation and hence should be preferred.

- Adding (2.8) and (2.9) we have

- $\mathrm{y}^{11}(\mathrm{x})=\frac{1}{h^{2}}\left[\mathrm{y}(\mathrm{x}+\mathrm{h})-2 \mathrm{y}(\mathrm{x})+\mathrm{y}(\mathrm{x}-\mathrm{h})+\mathrm{O}\left(\mathrm{h}^{2}\right)\right]$ which is the central difference approximation of $\mathrm{y}^{11}(\mathrm{x})$.

The accuracy of this method depends on the size of the sub-interval $h$ and also on the order of approximation. As we reduce $\mathrm{h}$ the accuracy improves but the number of equation to be solved also increases (Grewal, 1998).[4]

\section{SOLUTION APPROACH TO TEST PROBLEMS}

In this section the procedure used to evaluate the problem that will be solved in chapter four (4) are stated and discussed. These are linear differential equations with initial values. The two test problems are:

1. $3 x y^{11}+2 y^{1}+y=0$

2. $y^{11}+x^{2} y=0$

These problems will be solved using the finite difference approximation methods which is made up of the forward difference, backward and the central difference approximation formulae

The following procedures are essential:

(i) Dissolve the given differential equation into a difference equation

(ii) Choose a step size which must not be large

(iii) Next we evaluate $x_{i}$ at intervals between limit $x_{1}$ and the upper limit $x_{n}$ for $n$ interval, $i=1,2,3, \ldots \ldots$

(iv) Calculate for $\mathrm{y}^{11}, \mathrm{y}^{1}$ using $\mathrm{x}_{\mathrm{i}}, \mathrm{i}=1,2,3 \ldots \ldots$ and $\mathrm{h}$ from the forward, backward and central formulae

(v) Substitute $y^{11}, y^{1}$ and $y$ into the given equation then, evaluate for $y_{1}, y_{2}$, as the case may be, given boundary condition from the original equation. For the forward difference we have for the first derivative

And

$$
\mathrm{y}^{1}(\mathrm{x})=\frac{1}{h}\left[\mathrm{y}_{\mathrm{i}+1}-\mathrm{y}_{\mathrm{i}}\right] \ldots \ldots \ldots \ldots \ldots \ldots \ldots
$$

$$
\mathrm{y}^{11}(\mathrm{x})=\frac{2}{h^{2}}\left[2 \mathrm{y}_{\mathrm{i}+1}-2 \mathrm{y}_{\mathrm{i}}\right] \ldots \ldots \ldots \ldots \ldots . \quad 2.5
$$

For the forward difference approximation formulae, it is given by:

$\mathrm{y}^{1}(\mathrm{x})=\frac{y(x)-y(x-h)}{h}+\mathrm{O}(\mathrm{h})$ 
That is

$$
\mathrm{y}^{1}(\mathrm{x})=\frac{1}{h}\left[\mathrm{y}_{\mathrm{i}}-\mathrm{y}_{\mathrm{i}-1}\right] \ldots \ldots \ldots \ldots \ldots \ldots
$$

For the first derivative

And

$\mathrm{y}^{11}(\mathrm{x})=0$

For the second derivative

While for the central approximation formula, it is given by

$\mathrm{y}^{1}(\mathrm{x})=\frac{1}{2 h}\left[\mathrm{y}_{\mathrm{i}+1}-\mathrm{y}_{\mathrm{i}-1}\right] \ldots \ldots \ldots \ldots \ldots \ldots \ldots \ldots \ldots \ldots \ldots \ldots \ldots \ldots . \ldots . . .2 .8$

For the first derivative

And $\mathrm{y}^{11}(\mathrm{x})=\frac{1}{h^{2}}\left[\mathrm{y}_{\mathrm{i}+1}-2 \mathrm{y}_{\mathrm{i}}+\mathrm{y}_{\mathrm{i}-1}\right]$

for the second derivative.

\section{ERROR ESTIMATES AND STABILITY TEST}

After solving each problem, the error term will be evaluated to determine the stability and accuracy of solutions.

To calculate the error for the forward, backward and central difference approximation formulae, we use Taylor's theorem.

Assuming that $\mathrm{y}$ is continuously differentiable. The error is given by

$\frac{\Delta[y](x)}{h}-\mathrm{y}^{1}(\mathrm{x})-\mathrm{O}(\mathrm{h})(\mathrm{h} \rightarrow 0) \quad \ldots \ldots \ldots \ldots \ldots . . .10$

for the forward difference.

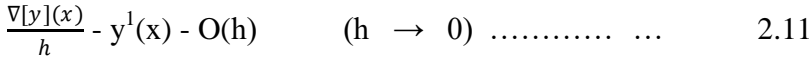

for the backward difference

and

$\delta[\mathrm{y}](\mathrm{x})-\mathrm{y}^{1}(\mathrm{x})-\mathrm{O}\left(\mathrm{h}^{2}\right)$

for the central difference approximation formulae

where

$\Delta$ is the forward difference operator

$\nabla$ is the backward difference operator

$\delta$ is the central difference operator

and

$\mathrm{y}^{\mathrm{l}}(\mathrm{x})=\lim _{h \rightarrow 0} \frac{y(x+h)-y(x)}{h}$

$\frac{\nabla[y](x)}{h}=\frac{y(x+h)-y(x)}{h}$

for the forward difference.

Equation 2.13 and 2.14 can be obtained also for the backward and central difference approximation formulae (Anes, 1977).[1]

The error estimate of each method used depends on the step size. For the central difference formula, the error estimation is of order $\mathrm{O}\left(\mathrm{h}^{2}\right)$ i.e. the central difference, while that of the forward and backward difference is of order $\mathrm{O}(\mathrm{h})$. And from our evaluation of error, the method that has the least error accumulation is termed to be a more efficient and accurate method.

\section{III.RESULTS AND DISCISSION}

Here, the result of the step by step derivation of solutions to differential equation via difference equation of problems 1 and 2 are produced below. This is done using the forward difference method, the backward difference method and the central difference method. Their solutions will be compared and the stability deduced.

Table 1: Result from Test Problem One

\begin{tabular}{|l|l|l|l|l|l|l|}
\hline \multirow{2}{*}{$\begin{array}{l}\text { Finite Difference } \\
\text { Approximation }\end{array}$} & \multicolumn{4}{|l|}{ Result } & \multicolumn{2}{l|}{ Calculated Error } \\
\cline { 2 - 7 } & $0(h)$ & $0(h)^{2}$ & \multicolumn{1}{|l|}{$x$} & Y1 & Y2 \\
\hline $\begin{array}{l}\text { Forward Difference } \\
\text { Method }\end{array}$ & $\frac{1}{3}$ & $(1 / 3)^{2}$ & $\begin{array}{l}x_{i} \\
=1,2,3\end{array}$ & 0.5190 & 0.50676 & 0.33 \\
\hline $\begin{array}{l}\text { Backward Difference } \\
\text { Method }\end{array}$ & $\frac{1}{3}$ & $(1 / 3)^{2}$ & $\begin{array}{l}x_{i} \\
=1,2,3\end{array}$ & 0.4286 & 0.3674 & 0.33 \\
\hline $\begin{array}{l}\text { Central Difference } \\
\text { Method }\end{array}$ & $\frac{1}{3}$ & $(1 / 3)^{2}$ & $\begin{array}{l}x_{i} \\
=1,2,3\end{array}$ & 0.5668 & 0.5529 & 0.11 \\
\hline
\end{tabular}

\section{Error Estimation for Test Problem One (1)}

To estimate the error in any of the methods used will depend on the step size. 
For the central difference approximation method, the error estimate is of order $\mathrm{O}\left(\mathrm{h}^{2}\right)$ and it is derived by substituting $\mathrm{h}$ into the squared $h\left(h^{2}\right)$.

To obtain the error estimate, it is given by:

Given $\mathrm{h}=1 / 3$ from the problem given, the error estimate for the central difference is

$\mathrm{O}\left(\mathrm{h}^{2}\right)=(1 / 3)^{2}=1 / 9=0.11$

The error estimate for the forward difference is of order $\mathrm{O}(\mathrm{h})$ and given by:

Given $\mathrm{h}=1 / 3$, the error estimate is

$\mathrm{O}(\mathrm{h})=1 / 3=0.33$ Thus the error is 0.33

For the backward difference, the error is of order $\mathrm{O}(\mathrm{h})$. Hence estimating the error given

$\mathrm{h}=1 / 3$

implies $O(h)=\frac{1}{3}=0.33$

Table 2: Result from Test Problem Two

\begin{tabular}{|c|c|c|c|c|c|c|c|}
\hline \multirow{2}{*}{\multicolumn{2}{|c|}{$\begin{array}{l}\text { Finite Difference } \\
\text { Approximation }\end{array}$}} & \multicolumn{5}{|l|}{ Result } & \multirow[b]{2}{*}{ Calculated Error } \\
\hline & & $O(h)$ & $0(h)^{2}$ & $x$ & $\mathrm{Y} 1$ & $\mathrm{Y} 2$ & \\
\hline $\begin{array}{l}\text { Forward } \\
\text { Method }\end{array}$ & Difference & $1 / 5=0 \cdot 2$ & & $\begin{array}{l}x_{i} \\
=1,2,3\end{array}$ & 0 & 0 & 0.2 \\
\hline $\begin{array}{l}\text { Backward } \\
\text { Method }\end{array}$ & Difference & $1 / 5=0 \cdot 2$ & & $\begin{array}{l}x_{i} \\
=1,2,3\end{array}$ & 0 & 0 & 0.2 \\
\hline $\begin{array}{l}\text { Central } \\
\text { Method }\end{array}$ & Difference & $1 / 5=0 \cdot 2$ & $(1)^{2}$ & $\begin{array}{l}x_{i} \\
=1,2,3\end{array}$ & 0.6681 & 0.3351 & 0.04 \\
\hline
\end{tabular}

\section{Error Estimate for Test Problem Two (2)}

For the central difference approximation method, the error is of order $\mathrm{O}\left(\mathrm{h}^{2}\right)$ and is obtained by substituting $\mathrm{h}$ in to squared $\mathrm{h}$ $\left(h^{2}\right)$ to estimate the error.

Given $\mathrm{h}=1 / 5$ in the second problem, the error estimate is

$O\left(h^{2}\right)=(1 / 5)^{2}=1 / 25=0 \cdot 04$

hence $\mathrm{O}\left(\mathrm{h}^{2}\right)=0.04$ for central difference

The error estimate for the forward difference is of order $\mathrm{O}(\mathrm{h})$. Hence given $\mathrm{h}=1 / 5$, the error estimate is

$O(h)=1 / 5=0 \cdot 2$ 
And for the backward difference the error is of the order $\mathrm{O}(\mathrm{h})$,

hence estimating the error given $\mathrm{h}=1 / 5$ we have

$O(h)=1 / 5=0 \cdot 2$

The numerical solutions of $\mathrm{x}(\mathrm{t})$ obtained by solving the two test problems using the three finite difference approximations as well as their computed errors are compared as follows:

\section{DISCUSSION}

After solving each problem their error estimates were determined, this was done in order to test the stability of each solution having used the various methods.

In problem one (1), using the forward difference and backward difference methods the error was large, but using the central difference method dampened the error, hence the error was minimized.

In problem two (2), using the forward and backward difference methods yield a trivial solution hence did not give any room for error analysis, but the central difference method gave a satisfying error estimate.

From the values of the errors obtained we observed that the error accumulated by the other difference methods were larger than the error accumulated by the central difference formula.

\section{Observations:}

(1) The error of the numerical solution increases with number of steps.

(2) These error are referred to as "accumulative errors"

(3) Step size definitely has strong effects on the accuracy of finite difference method

\section{CONCLUSION}

Evaluating from the error values obtained from the forward, backward and the central difference methods of finite difference approximation formulae, we observed that the central difference method is more accurate reason being that its error is dampened and this assumes stability of solution. Hence difference equation and its method of differences as a whole is seen as an effective means of evaluating differential equations however complex or difficult they might appear

\section{REFERENCES}

[1] Anes, W.F. (1977).numerical methods for partial differential equations. Academic press,

New York

[2] Baker, D. I.(1995a).Applying Higher order diric time steps to the 'modified Picard' method. GROUND

WATER 33(2):259-263

[3] Beny Neta and Jerome O. Igwe: Finite Differences versus Finite Elements methods for solving nonlinear integro- differential equation; Journal of Mathematical Analysis and Application; Vol12, Issue3, December,1985

[4] Grewal, B.S. (1998). Numerical methods in engineering and science. Khanna Publishers, India.

[5] Gupta.(2004). Mathematical Physics.Mc Graw hill, Boston.

[6] Karline Soetaert,Thomas Petzoldt and R Woodrow Setzer: Solving Differential Equations in R;The R Journal, Vol2/2,, December 2010,Pp1-11,ISSN2073-4859

[7] Kreyszig, E. (1999).advance engineering mathematics ( $8^{\text {th }}$ edition). John Wiley and sons, New York.

[8] Mathews, J. H., Fink, K. D. (2004). Numerical Methods using MATLAB (4 ${ }^{\text {th }}$ Edition)Prentice-hall, New York USA.

[9] OdiorA.O. (2003).Mathematics for Science and Engineering Students. Third Edition. Ambik Press, Benin City, ISBN978-027289-5.

[10] Olayi, G. A (2000) Introductory Numerical Methods. Ahmadu Bello university Press, Zaria

[11] Olayi, G.A. (2001). Mathematical Methods. Bachudo Publishers, Calabar

[12] Peter Philip (July 22, 2016): Ordinary Differential Equations; Lecture Notes Originally Created for the Class of Spring Semester 2012 at LMU Munich, Revised and Extended for Several Subsequent Classes July 22, 2016

[13] Stein, C, Larmen, T.H. Eleiserson C., and Riverst, R.L.(1990). Introduction to Algorithms(2 ${ }^{\text {nd }}$ edition).Mit Graw-Hill, U.S.A

[14] Stroud, K.A(1996). Further Engineering Mathematics ( $3^{\text {rd }}$ Edition). Palgrove, New York. 